|| ISSN(online): 2589-8698 || ISSN(print): 2589-868X ||

International Journal of Medical and Biomedical Studies Available Online at www.ijmbs.info

NLM (National Library of Medicine ID: 101738825)

Index Copernicus Value 2019: 79.34

Original Research Article

Volume 5, Issue 9; September: 2021; Page No.160-162

\title{
CLINICAL PROFILE AND OUTCOME OF CHILDREN ADMITTED WITH STATUS EPILEPTICS
}

\author{
Dr. Sushil Kuamr Bakolia ${ }^{1}$, Dr. Gajendra Kumar Verma ${ }^{2}$, Dr. Dinesh Kumar Barolia ${ }^{3}$ \\ ${ }^{1}$ MD (Paediatrics), Assistant Professor, Govt. S.K. Medical College \& AG Hospital, Sikar (Rajasthan) \\ ${ }^{2} \mathrm{MD}$ (Paediatrics), Senior Resident, SMS Mc, Jaipur \\ ${ }^{3} \mathrm{M}$ Ch (Peadiatric) Surgery, Assistant Professor, J L N Mc, Ajmer
}

Article Info: Received 05 August 2021; Accepted 19 September 2021

DOI: https://doi.org/10.32553/ijmbs.v5i9.2207

Corresponding author: Dr Dinesh Kumar Barolia

Conflict of interest: No conflict of interest.

\begin{abstract}
Background: Objective of this study was to study epidemiology and clinical profile of Status epilepticus

Methods: Hospital based cross sectional study conducted on 50 children All children aged between 1 month to 12 years who at presentation or during the PICU stay had convulsive status epilepticus - defined as continuous seizure activity or recurrent seizure activity without regaining consciousness lasting for $>5 \mathrm{~min}$.

Results: Among 50 children $56.00 \%$ were in the age group were less than 5 years , $24 \%$ were between $6-10$ years ,20.00\% were above 10 yrs. The mean age group was $6.21 \pm 1.26$ years. Incidence was higher in males $(64 \%)$ when compared to females (36\%). Generalized tonic clonic seizure were observed in $46(92.00 \%)$ and partial seizure was noted in $4(8 \%)$ of the children. About 36 (72\%) of the children developed SE for the first time.

Conclusion: Status epilepticus is one of the common neurological emergency which requires admission to PICU. In our study epilepsy is one of the most common causes of status epilepticus. Early and appropriate treatment with anticonvulsants and use of mechanical ventilation may improve the outcome.
\end{abstract}

Keywords: Status epilepticus, mortality, clinical profile

\section{Introduction}

Status epilepticus (SE) is a common life-threatening emergency that requires prompt recognition and management. ${ }^{1}$ SE can represent an exacerbation of a preexisting seizure disorder, the initial manifestation of a seizure disorder, or an insult other than a seizure disorder resulting in seizures.

The classical definition of SE requires that seizures (continuous or intermittent without return to baseline mental status) last for a minimum of 30 minutes. However, seizures which last longer than 5 minutes are unlikely to stop spontaneously. ${ }^{2}$ As part of operational definition put forth within the past few years, status epilepticus is defined as continuous seizure activity or recurrent seizure activity without regaining consciousness, lasting for more than 5 minutes. The use of operational definition allows early treatment before the seizure becomes refractory to antiepileptic drugs.4 Prolonged status epilepticus can lead to various complications such as cardiac dysrhythmia, metabolic derangements, autonomic dysfunction, neurogenic pulmonary oedema, hyperthermia, pulmonary aspiration and even permanent neurological damage. Approximately 4-10\% of children experience one episode of seizure within first 16 years of life. Approximately $30 \%$ of patients presenting with status epilepticus are having their first seizure. Status epilepticus is most common in children younger than 5 years of age with an incidence of $>100$ per 100,000 children. Convulsive status epilepticus (CSE) is most common form of status epilepticus and accounts for about $90 \%$ of all SE in children. Mortality from status epilepticus varies from $3-50 \%$ in different studies. ${ }^{3,4}$

\section{Material and Methods}

\section{Study Design:}

Hospital based prospective study

Study Population:

All children aged between 1 month to 12 years who at presentation or during the PICU stay had convulsive status epilepticus - defined as continuous seizure activity or recurrent seizure activity without regaining consciousness lasting for $>5 \mathrm{~min}$.

\section{Inclusion Criteria:}

All children aged between 1 month to 12 years who at presentation or during the PICU stay had convulsive status epilepticus - defined as continuous seizure activity or recurrent seizure activity without regaining consciousness lasting for $>5 \mathrm{~min}$. 


\section{Exclusion Criteria:}

Patients in whom the information regarding seizure duration will be incomplete or unclear.

\section{Data Collection:}

Informed consent will be obtaine from parents or guardians of the children included in the study. The duration of status epilepticus will be ascertaine from a reliable patient's relative or attendant, medical records and referring physician's note. After securing airway, breathing and circulation all the patients will be managed with standard treatment protocol.

Once the child will be stabilize, data which included age, sex, duration of seizures before and after admission, type and number of antiepileptic drugs (AEDs) used for control of status epilepticus (SE), history of previous seizure pattern, adherence to treatment, perinatal, developmental, family history and history of coexisting medical conditions will be recorde.

General physical examination and detailed neurological examination will be performe. Investigations like complete blood count, blood chemistries including serum calcium, random blood sugar, serum sodium, urea and creatinine, neuroimaging, CSF examination, Electroencephalography
(EEG) will be performe as required to ascertain etiology and guide management. Further, during the hospital stay, recurrence of seizures, subsequent need for intubation and mechanical ventilation and days spent in PICU will be note. Type and etiology of status epilepticus will be classifie as per report of the International League Against Epilepsy (ILAE) task force on classification of status epilepticus.

Refractory status epilepticus (RSE) was defined as seizures which persist despite the administration of two appropriate anticonvulsants at acceptable doses, with a minimum duration of status of 60 minutes (by history or on observation). Though febrile seizures are a part of acute symptomatic etiology, it has been considered separately for analysis as it is likely to erroneously amplify the severity of febrile seizures and dilute the severity of acute neurological insults.

\section{Data Analysis:}

All data were analyzed on EPI-info statistical software. Qualitative data were expresse in the form of proportion. Quantitative data were expresse in mean \pm SD. Qualitative data were compare by Chi square test. Unpaired $t$ test will be use to infer the difference in means.

\section{Results}

Table 1: Demographic Profile

\begin{tabular}{|l|l|l|l|}
\hline \multicolumn{2}{|c|}{} & No of cases & Percentage \\
\hline \multirow{3}{*}{ Age } & $0-5$ Yrs & 26 & 52.00 \\
\cline { 2 - 4 } & $6-10$ Yrs & 12 & 24.00 \\
\cline { 2 - 4 } & $>10$ Yrs & 12 & 24.00 \\
\hline \multirow{3}{*}{ Sex } & Male & 31 & 62.00 \\
\cline { 2 - 4 } & Female & 19 & 38.00 \\
\hline
\end{tabular}

Among 50 children $52.00 \%$ were in the age group were less than 5 years , $24 \%$ were between $6-10$ years, $24.00 \%$ were above $10 \mathrm{yrs}$. Incidence was higher in males (64\%) when compared to females (36\%).

Table 2: Clinical profile

\begin{tabular}{|l|l|l|l|}
\hline Seizure type & GTCS & 46 & 92.00 \\
\cline { 2 - 4 } & Partial & 4 & 8.00 \\
\hline Nausea / vomiting & 9 & 18.00 \\
\hline Fever & 28 & 56.00 \\
\hline Faecal and urinary incontinence & 7 & 14.00 \\
\hline Headache & 11 & 22.00 \\
\hline Developmental delay & 13 & 26.00 \\
\hline Respiratory infection & 5 & 10.00 \\
\hline Hospital stay & $3.12 \pm 2.06$ days & \\
\hline Mortality & 3 & 6.00 \\
\hline
\end{tabular}


Generalized tonic clonic seizure were observed in 46 (92.00\%) and partial seizure was noted in 4 (8\%) of the children. About 36 (72\%) of the children developed SE for the first time.

\section{Discussion}

In this study, it was found that children less than five years of age comprised the majority of the cases (56.00\%). Other studies have also found a higher prevalence in the younger age group. As the first episode of convulsion has been theorized to be due to the underdeveloped mechanisms for control of seizure activity, there is a disruption of neuronal function with minimal abnormalities in younger children. Also, younger age is more vulnerable to acute etiologies including febrile seizures. ${ }^{5,6}$

In present study, the sex distribution shows slightly higher incidence of status epilepticus in males than females. Although they were almost in equal propotions, many other studies done both in pediatrics and adults shows similar type of results Gulati S observed 22 (70\%) patients out of 31 were male. ${ }^{7}$

It was observed that GTCS type of seizure is the commonest of all 4 types similar incidence was observed by Kwong $\mathrm{KL}^{8}$ and Gulati et al. ${ }^{7}$

\section{Conclusion}

Status epilepticus is one of the common neurological emergency which requires admission to PICU. In our study epilepsy is one of the most common causes of status epilepticus. Early and appropriate treatment with anticonvulsants and use of mechanical ventilation may improve the outcome.

\section{References}

1. Pellock JM. Status epilepticus in children: update and review. J Child Neurol. 1994;9(2):27-35

2. Mikati MA, Hani AJ. Status epilepticus. In: Kliegman R, Behrman R, Nelson W. Nelson textbook of pediatrics, 20e; Elsevier; 2016:2854- 2855.

3. Trinka E, Cock H, Hesdorffer D, Rossetti AO, Scheffer IE, Shinnar S, et al. A definition and classification of status epilepticus-Report of the ILAE Task Force on Classification of Status Epilepticus. Epilep. 2015;56(10):1515-23.

4. Madhu PK, Krithika R. Convulsive status epilepticus in children: clinical profile and outcome in a tertiary care hospital. Int J Contemp Pediatr 2019;6:xxx-Xx

5. Hauser WA. Status epilepticus: epidemiologic considerations. Neurology. 1990;40:S9-S13.

6. Treiman DM, Meyers PD, Walton NY, Collins JF, Colling C, Rowan AJ, Handforth A, Faught E, Calabrese VP, Uthman BM, Ramsay RE. A comparison of four treatments for generalized convulsive status epilepticus. New Engl J Medicine. 1998;339(12):792-8.

7. Gulati S, Kalra V, Sridhar MR. Status Epilepticus in Indian Children in a tertiary care center. Indian $\mathrm{J}$ Pediatruics, 2005;72:105-8

8. Kwong KL, Lee SL, Yung A, Wong VC. J Child Health. 1995(5):395-8. 